\title{
Isolation of Biocidal Compounds of Calotropis Latex and their in vitro and in vivo Effect on the Mortality of Root Knot Nematode (Meloidogyne javanica) in Brinjal and Chilli
}

\author{
Lalit Kumar $^{1 *}$, Abhilasha Srivastava ${ }^{2}$, Bansa Singh ${ }^{1}$ and A.P. Khare ${ }^{1}$ \\ ${ }^{1}$ Indian Institute of Pulses Research, Kanpur, India \\ ${ }^{2}$ (WOS-B), Department of Science and Technology, New Delhi, India \\ *Corresponding author
}

\section{Keywords \\ Root knot nematode (Melidogyne javanica)}

\section{Article Info}

Accepted:

26 March 2018

Available Online:

10 April 2018

\section{A B S T R A C T}

An attempt was made to find out natural and cheaper methods for the control of vegetable pest. Locally available plant $C$. procera was used and a good methodology was developed to extract the secondary metabolic compounds from the latex. Secondary metabolic compounds extracted in form of different polarity fractions and in purity of $>90 \%$ as single pure compound in each fraction, showed tremendous activity in vitro test against secondary stage juveniles of Meloidogyne javanica. The extracted fractions were found toxic to juveniles by different capabilities between concentrations ranged from 50-300 $\mu \mathrm{g}$ $\mathrm{ml}^{-1}$. The activity of compounds was found dependent on concentration, time of exposure and the polarity of the extracted fractions. Two highly lipophilic nature of fractions having clear solubility in solvents such as hexane, dichloromethane were found extremely active by giving larval mortality of test nematode by more than $90 \%$ at their $250 \mu \mathrm{g} \mathrm{ml}^{-1}$ concentrations, after an exposure period of $48 \mathrm{hr}$. whereas, quick and absolute mortality in these fractions was observed at $300 \mu \mathrm{g} \mathrm{ml}^{-1}$ concentrations. Ethyl acetate soluble fraction also gave more than $80 \%$ mortality of test nematodes at 250 and $300 \mu \mathrm{g} \mathrm{ml}^{-1}$ concentrations, after an exposure period of $48 \mathrm{hr}$. A high concentration viz., $1000 \mu \mathrm{g} \mathrm{ml}^{-1}$ of the fraction especially derived from polar part of latex and found soluble in methanol was required to bring about $80 \%$ juvenile mortality of the test nematode that to after an exposure period of $72 \mathrm{hrs}$. The EC formulations developed from non-polar fractions during their bio-efficacy test in pots also revealed a good control of nematode gall formation on roots of brinjal and chilli which on turn found to enhance yield of both of the crops to a great extent. As compare to control, the three formulations especially developed from hexane, dichloromethane and ethyl acetate soluble fractions were found to control nematode galls on root nearly to $50 \%$ on brinjal and $40 \%$ on chilli at their concentrations of $1.25 \mathrm{~g} / \mathrm{pot}$. The formulations at this concentration also gave a yield enhancement of 70 $100 \%$ and $50-60 \%$ respectively in case of brinjal and chilli as compare to control.

\section{Introduction}

The root knot nematodes (Meloidogyne spp.) are sedentary endoparasites and most damaging agricultural pests, attacking a wide range of vegetable crops. Apart from the economic loses; nematodes are also adversely affecting the quality of these crops. In India, 
root-knot nematodes (Meloidogyne spp.) are reported to cause yield losses to the tune of 39.7 to $46.0 \%$ (Bhatti and Jain, 1977; Reddy, 1985) therefore, a number of tactics were adopted to bring out plant parasitic nematode population below threshold level. The control of plant-parasitic nematodes is more difficult owing of their inhibition under the soil and attacking the underground plant parts. To manage nematode population below threshold level certain control measures such as Cultivation of resistant varieties, cultural practices such as crop rotation, cover cropping, green mannuring, organic amendments, chemical nematicides etc. have been adopted. Recently, the control of plant parasitic nematodes by using conventional nematicides has declined internationally because of the inherent toxicity of many existing synthetic pesticides to non-target organisms and their persistence in the environment (Taylor, 2000). Since, root-knot nematodes are known to have wide host ranges thereby, that too limits the utility of cultural control tactics like crop rotations, green manures, and cover crops. Because of this, the uses of botanicals for nematode management are presently gaining attention as they are eco-friendly, cost effective and compatible with other bio-control agents i.e. agrochemicals, moreover, they are comparatively less liable to produce any residual effects on their application. Many plants were reported to possess antagonistic chemicals against plant parasitic nematodes. The extracts from number of plants/plant products and extracts with organic solvents etc. were found to contain nematicidal and nematostatic compounds (Siddiqui et al., 1987; Prakash and Rao, 1977; Muhammad et al., 2001; Das and Mishra, 2003). Few plants also exhibit antagonistic nature by the production of secondary volatile and nonvolatile exudates from their different parts viz., leaf, flower, root and stem. Plant based products are not only inhibitory to nematodes but also offer opportunities to generate new, safe, and better control measures for plant parasitic nematodes (Gommers, 1981; Chitwood, 2002; Pandey et al., 2001). In this respect, Calotropis spp. latex was also found quite effective against a variety of nematodes. $100 \%$ mortality in J2 of Meloidogyne incognita in treatments of Calotropis procera latex was not only reported by Prasad (2002) but also documented by several others (Vijaylakshmi and Goswami, 1995; Siddiqui et al., 1987; Haseeb and Shukla, 2004; Upadhayay et al., 2003 and Sundararaju et al., 2003). Though all these studies mainly remained focus either on the use of aqueous or organic solvent based extracts of leaves, bark and stems or the soil amendments of aerial parts of plant but information on its toxic principles is still lacking in literature. Moreover, this is only the plant in nature found free from pest and pathogen attack and also considered as a toxic plant in general public opinion which itself indicates about the preponderance of toxic compounds inherent in it. Therefore, it was felt imperative to isolate, separate and characterize the major toxic compounds of Calotropis latex for their in vitro efficacy assessment against second stage juveniles Meloidogyne javanica and subsequently vivo test in pots on brinjal and chilli crops. The generated information is of great use for management of nematode population below threshold level and as a first step in search of plant based and environmentally safe nematicides or as a clue to make synthetic analogues.

\section{Materials and Methods}

\section{Latex collection}

Latex was collected by making small and shallow cuts at different places of leaves and other aerial parts of plants, grown wildly in local areas in the vicinity of Indian Institute of Pulse Research, Kanpur, India. Approximately 
three liter of latex was collected in one month by engaging three labors for 3 to $5 \mathrm{~h}$ daily.

\section{Laboratory solvents and chemicals}

All solvents of commercial grade $(\mathrm{CDH}(\mathrm{P})$ LTD., New Delhi and Sarabhai-Merck Chemicals, Bombay, India) were purchased from commercial suppliers and used for extraction, without further purification. EL and HPLC grade solvents of same manufacturers were employed for further purification of extracted compounds. Commercial grade xylene (BDH Laboratories, Bombay, India) and tween-80 (S.D. FINECHEM LTD, Mumbai) were respectively used as formulation solvent and surfactant. Silica gel-G (column chromatography \& TLC grades) and cellulose powder microcrystalline (TLC grade) of Merck made were utilized for column chromatography and thin layer chromatography.

\section{Test organism}

Second stage juvenile $\left(\mathrm{J}_{2}\right)$ and egg masses of root knot nematode (Meloidogyne javanica) were used as test organism in this study. To maintain regular population of juveniles during experimentation, egg masses of the test nematode were collected from the infected brinjal roots and further cultured on brinjal plants at $24+1{ }^{\circ} \mathrm{C}, 70-75 \%$ relative humidity, and 16/8 h light/dark cycle were used.

\section{Extraction of compounds and their fractionation}

Collected latex was systematically processed in different lots of approximately $200 \mathrm{ml}$ each. For successful recovery of compounds, in the beginning, appropriate amount of latex was stirred with a mixture of $500 \mathrm{ml}$ ethyl acetate and dichloromethane (50:50) for two hours at ambient conditions and filtered. Residue remained on filter paper again stirred with
$500 \mathrm{ml}$ of a solvent mixture of acetone: methanol (50:50) and filtered. At this time, residue remained on filter paper was discarded. Both of the filtrates were analyzed via TLC to detect and know the number of individual compounds present and their polarity. Though, on TLC both of the fractions revealed the common compounds at different Rt values, but fraction first (ethyl acetate: dichloromethane) was found enriched with the non-polar compounds whereas, the second one (acetone: methanol) was found to enriched with the polar compounds. By repeatedly following the column chromatographic techniques both of the fractions were purified further for their authentic solubility between polar and non-polar. Both of the polar and non-polar fractions were processed further for recovery of sub fractions constituting of approximately 3 to 4 individual chemicals by following the fractionation scheme as depicted in figure 1.

\section{Preparation of formulations and test concentrations}

Obtained all the four fractions were converted to suitable emulsifiable concentrate (EC) formulations of $10 \%$ in order to achieved uniform solubility. The emulsification of fractions was achieved by combining the isolated crystallized products with pesticide dispersible liquid carriers and with carrier vehicle assistants, i.e. emulsifying agent and/or dispersing agents. 10\% EC formulations were prepared by using the tween-80 (10\%) as emulsifier and cyclohexanone as dispersible liquid carriers.

Emulsifications in recipes were achieved by vigorously agitating the mixtures at high speed and at $45+2^{0} \mathrm{C}$ for an hour. Test solutions of different concentrations viz., 50, 100, 150, 200, 300, 400, 500, 600, 700, 800, 900 and $1000 \mu \mathrm{g}$ $\mathrm{ml}^{-1}$ were prepared by taking the appropriate amount of EC. 


\section{Bioassay}

Experiments were conducted on freshly hatched second stage juveniles in six different dilutions in 50-mm diameter petriplates of approximately $15-\mathrm{ml}$ capacity. Initially $9 \mathrm{ml}$ distilled water was poured in each test petriplates then required quantity of test $\mathrm{EC}$ formulation was added in accurate amount to get the desire concentration in final volume of $10 \mathrm{ml}$ and mixed well. One $\mathrm{ml}$ of freshly hatched second stage juveniles of $M$. javanica suspension containing approximately 300-400 in number was added to each petriplate and kept at $25+1^{\circ} \mathrm{C}$ for 24,48 and $72 \mathrm{~h}$. All the treatments were replicated thrice along with a set of control containing formulation auxiliary's viz., cyclohexanone and tween- 80 similarly prepared. After specified period of incubation, the treated suspension in petriplates was stirred properly and one $\mathrm{ml}$ suspension was transferred to another petriplate. It was diluted 10 times with distilled water to reduce the concentration of chemical much below to its toxic level to observe the possibility of revival if any. Observations on live and dead nematodes were recorded after $24 \mathrm{hr}$. of dilution by using stereoscope microscope. Dead nematodes appeared straight, while leave nematodes retained the characteristic sigmoid shape and exhibited movement (Sethi and Prasad, 1962). The per cent mortality was worked out from the average of three replications in each case and converted to natural mortality according to Abbots formula.

\section{Pot experiments}

Pot culture experiments for both of the crops i.e. brinjal and chilli were conducted in big size pots of 20 inches diameter during March to June. The pots were filled by taking approximately $12-15 \mathrm{~kg}$ of ordinary soil belongs to Indo-Gangatic Plain. It is a sandy loam texture soil of taxonomical class Typic
Usrtochrept and was found to retain physicochemical properties as $\mathrm{pH}-7.5$, organic carbon $0.50 \%$, available $\mathrm{N}, \mathrm{P}$ and $\mathrm{K}$ $150,250,200 \mathrm{Kg} / \mathrm{h}$. Three to four seeds of brinjal (Pusa-long) and chilli (G-5, a local cultivar) were sown separately in each pot where after germination plants were thinned to one 1 per pot. After 10 days of germination the soil of pots was initially incubated with freshly hatched second stage juveniles of $M$. javanica@500 per pot approximately. After $48 \mathrm{hr}$. of incubation the pots were treated with different concentrations viz., 0.750, 1.00, 1.25 $\mathrm{g} /$ pot of EC formulations of fractionated chemicals. The chemicals were applied to the surface of pots after dissolving the appropriate quantity of EC formulations in one liter of water. Whereas, one set of pots for each crop was kept as control where no chemical treatment was made. All treatments were replicated thrice. The pots were arranged in a completely randomized design in the greenhouse at $25 \pm 5^{\circ} \mathrm{C}$ for nearly 90 days. Sufficient moisture in pots was maintained by applying irrigation as and when required. Observations on the plant characters viz., shoot length, shoot weight, root length and root weight, gall index etc. and yield \& yield attributing parameters were taken at the time of termination of experiment. Root-knot index was assessed on 0-5 scale (Sasser et al., 1984).

\section{Data collection and statistical analysis}

After termination of the experiments the plants of both of the crops were gently removed from the pots. The shoots were counted and excised from the roots. The lengths of shoots and roots were measured with a ruler. The shoots and roots of individual plants were weighed with an electric balance. The galls and egg masses on the whole root systems were counted under a stereoscope at a magnification of $40 \mathrm{X}$. The obtained data's from both of the experiments viz., lab and pot were statistically analyzed by 
using SPSS software. And the differences between treatments were determined by LSD $5 \%$ probability level.

\section{Results and Discussion}

\section{Composition of latex and recovery of chemicals}

As per extraction and fractionation scheme fallowed by us (Fig. 1) we got success in fractionation of entire chemicals present in latex into various groups of distinct polarity range (elotropic values ranging from 0 to 7 ). The entire latex was found to constitute of water $(86.904 \%)$, insoluble materials $(2.34 \%)$, and solid biochemicals (13.096\%). Out of total $13 \%$ of solid chemicals of latex nearly $90 \%$ were of lipophilic nature hence found clearly soluble in solvents of low elotropic values (02.75) such as hexane, dichloromethane, ethyl acetate, petroleum ether etc. and remaining $10 \%$ were of polar nature generally showed solubility in solvents of having elotropic values 4.0 or above. Since the chemical compounds present in non-polar fraction was found to possess narrow solubility range (0$<2.0$ ) hence these chemicals from the mixture were successfully fractionated in three subfractions of constituting either single or maximum 2-3 compounds by repeatedly following the fractional crystallization technique conducted by involving the effect of reduced temperature, and pressure. By following this step nearly $60 \%$ success was achieved to further fractionate the chemical mixture into three sub group of very close polarity range. The obtained three groups of compounds were again purified to have more than $90 \%$ of identical solubility of fractions of those showed clear solubility in (1) hexane/nhexane/petroleum ether, (2) dichloromethane/ chloroform and (3) ethyl acetate by using column chromatographic techniques. From polar portion of latex, only the compounds those possess solubility in methanol/ acetone were recovered successfully by following fractional crystallization technique. On TLC (conducted by using hexane as mobile phase) hexane soluble compound was found to retain a total of 3 compounds on Rf zone of 0.971 , 0.912 and 0.821 out of which only one at Rf 0.971 detected as major component of the fraction by retaining more than $90 \%$ area of total spot of the mixture. Dichloromethane fraction resolved by using 70:30 mixture of hexane: dichloromethane was found to retain only one single compound concluded by observing only one single spot at $\mathrm{Rf}$ zone 0.925 , while the ethyl acetate soluble fraction was found to retain 4 compounds in approximately equal concentration on TLC developed by using 60:40 mixture of hexane: ethyl acetate. Methanol soluble fraction on TLC (80:20:: acetone: methanol) was detected as a mixture of several compounds.

\section{Effect on $2^{\text {nd }}$ stage juveniles of root knot nematode}

The nematicidal activity of all the four formulations developed from different polarity of extracted fractions of calotropis latex varied according to the polarity of the fraction, doses and the incubation period. Results revealed in table 1, clearly indicated that formulations especially developed from the non-polar fractions of having solubility in low elotropic value solvents viz., Hexane, Dichloromethane and Ethyl acetate exhibited severe impact on the mortality and paralyses of second stage juveniles of Meloidogyne javanica in comparison to the formulations developed from polar fraction i.e. methanol soluble. Among polar fraction based EC Formulations the recipes especially developed from most non-polar fractions i.e. hexane and dichloromethane was found extremely active in respect of juveniles mortality of test nematode followed by the formulations developed from Ethyl acetate fraction. Whilst, the EC formulation developed from polar 
fraction observed least effective. Thus, it has been concluded that the polarity factor of the extracted fractions of calotropis latex is most critical parameter in determination of the toxicity against second stage juveniles of Meloidogyne javanica. Hexane and Dichloromethane fractions based formulations were found detrimental to the juveniles even at very low concentrations ranging from 50$300 \mu \mathrm{g} \mathrm{ml}{ }^{-1}$. The activity of both of the formulations was found highly correlative with time of exposure and the concentration of the formulation. At $100 \mu \mathrm{g} \mathrm{ml}^{-1}$ concentration, these formulations, gave nearly 25 and $10 \%$ respective juveniles mortality after an exposure period of $24 \mathrm{hr}$. as compare to control.

But there was a progressive and highly significant increase in the mortality with the increase in exposure period and the concentration of formulation. The formulations at same concentration resulted nearly $30-40 \%$ nematode mortality after exposure periods of 48 and $72 \mathrm{hrs}$. Quick and absolute mortality was observed at their highest concentration viz., $300 \mu \mathrm{g} \mathrm{ml}^{-1}$ at this concentration not a single nematode was found to survive even after $24 \mathrm{~h}$ of exposure. Even at $250 \mu \mathrm{g} \mathrm{ml}^{-1}$ the formulations were found quite effective by producing approximately $90 \%$ kill in juveniles after an exposure period of $72 \mathrm{hr}$. The results were found almost at par in respect of all these toxicological parameters in treatments of the EC formulation developed from Ethyl acetate soluble fraction. Formulations developed from methanol soluble fraction that retained $>80 \%$ as polar character was found moderately toxic to the second stage juveniles of $M$. javanica. The formulation was only found active with different capabilities between the concentrations ranging from 500-1000 $\mu \mathrm{g} \mathrm{ml}^{-1}$ however, in this case also a good correspondence between the formulation concentrations and time of exposures with the activity of formulations was observed. The formulation was found most active by being producing nematode juvenile kill to nearly $80 \%$ at $1000 \mu \mathrm{g} \mathrm{ml}^{-1}$ concentration after an exposure period of $72 \mathrm{hr}$. Our results are in good agreement with several other co-author findings. Nazir (2013) also reported nearly $60 \%$ mortality in juvenyl and $99.83 \%$ reduction in egg hatch of Meloidogyne incognita in treatments of leaf extract of Calotropis procera. Verma et al., (1989) demonstrated the toxicity of methanol extracts of Ricinus communis, Calotropis procera and Nerium oleander against $M$. javanica, Anguina tritici and Tylenchulus semipenetrans. Acetone extracts of Euphorbia pulcherrima (leaf), Ricinus communis (seed), Spigelia anthelmia (leaf) and Calotropis procera (root bark) also showed promise at varying levels in suppression of cyst development for control of Heterodera sacchari after their use either as singly or in combination (Salawu, 1992a). Abid et al., 1997 reported $100 \%$ mortality of $M$. javanica juveniles in treatments of calotropis extracts. Sheth, 2011; Begum et al., 2013, propose this plant as potential alternatives to chemical pesticides owing to be of its tremendous activity against root knot nematodes. The work on its chemical part was reviewed by Kumar et al., 2013 where the plant is being reported to contain various chemicals which are useful for various activities. The entire plant has been reported to contain flavonoids, alkaloids, sterols, triterpenoids, cardiac glycosides and usharin.

\section{Effect on gall formation and yield of brinjal and chilli}

The effectiveness of most active non-polar fraction based $\mathrm{E} \mathrm{C}$ formulations of calotropis latex metabolic products was studied in big pots of 20 inches size by using sandy clay loam soil as filer on two vegetable crops i.e. brinjal and chilli. 
Fig.1 Extraction procedure of secondary metabolic compounds of Calotropis procera latex

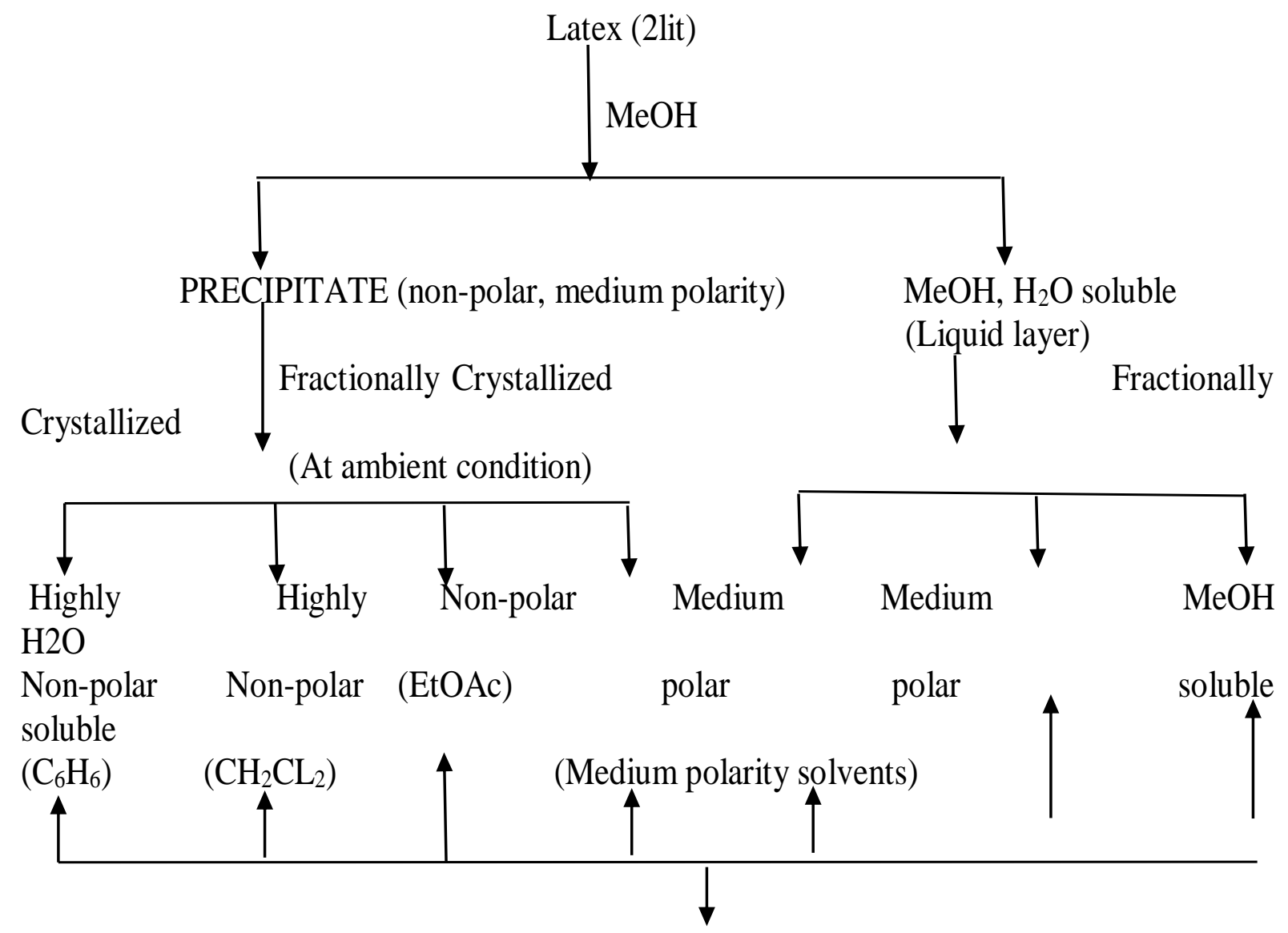

Crystallized nearly to 8 times by giving the effect of solvent strength, temperature and pressure
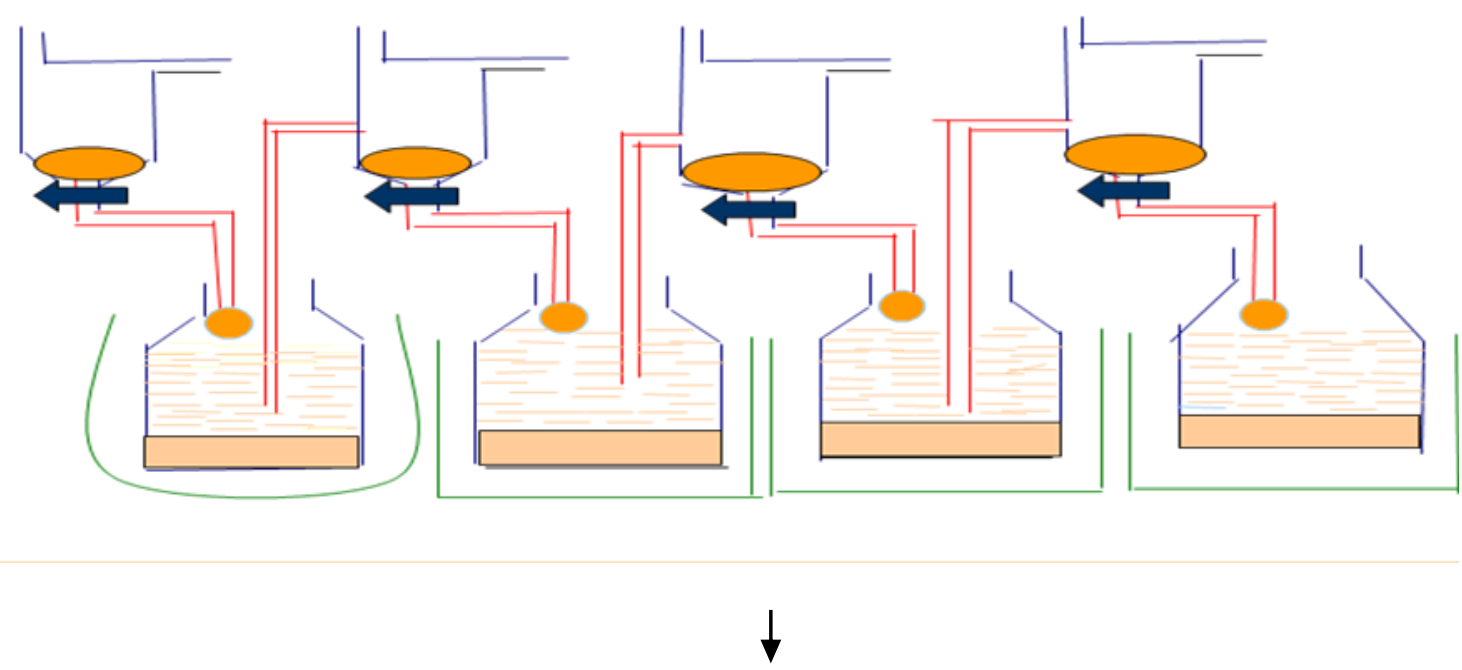

Authentic solubility of fractions of $>90 \%$ purity 
Table.1 Effect of different polarity fractions of calotropis latex on the mortality of second stage juvenile (J2) of Meloidogyne javanica at different concentrations and time exposures

\begin{tabular}{|c|c|c|c|c|c|c|c|c|c|c|c|c|c|c|}
\hline \multirow[t]{2}{*}{$\begin{array}{l}\text { Exposure } \\
\text { time (hr.) }\end{array}$} & \multicolumn{14}{|c|}{ Concentrations } \\
\hline & 50 & 100 & 150 & 200 & 250 & 300 & 500 & 600 & 700 & \multicolumn{2}{|l|}{800} & 900 & 1000 & Mean \\
\hline \multicolumn{15}{|c|}{ Effect of non-polar fraction (hexane soluble) } \\
\hline 24 & $3(9.4)$ & $24(29.3)$ & $30(33.2)$ & $45(42.1)$ & $95(76.9)$ & $100(90.0)$ & & & & & & & & $49.4(46.8)$ \\
\hline 48 & $9(17.0)$ & $32(34.2)$ & $36(36.9)$ & $52(46.2)$ & $95(77.7)$ & $100(90.0)$ & & & & & & & & $53.9(50.3)$ \\
\hline 72 & $\begin{array}{l}18(25.0 \\
)\end{array}$ & $41(39.8)$ & $49(44.2)$ & $65(53.8)$ & $99(87.3)$ & $100(90.0)$ & & & & & & & & $62.0(56.7)$ \\
\hline Mean & $\begin{array}{l}10(17.1 \\
)\end{array}$ & $32(34.4)$ & $38(38.1)$ & $54(47.3)$ & $96(80.6)$ & $100(90.0)$ & & & & & & & & \\
\hline \multicolumn{15}{|c|}{ CD $(\mathrm{P}=0.05)$, Time=1.62, Concentration=2.29, Time $\mathrm{X}$ Concentration=3.97 } \\
\hline \multicolumn{15}{|c|}{ Effect of non-polar fraction (soluble in dichloromethane) } \\
\hline 24 & $0(1.9)$ & $10(17.8)$ & $21(27.1)$ & $29(32.7)$ & $92(73.9)$ & $98(84.0)$ & & & & & & & & $42(39.6)$ \\
\hline 48 & $7(15.6)$ & $16(23.2)$ & $27(31.5)$ & $36(36.9)$ & 93(75.1) & $99(87.3)$ & & & & & & & & $46(44.9)$ \\
\hline 72 & $\begin{array}{l}15(23.0 \\
)\end{array}$ & $30(33.2)$ & $41(39.6)$ & $54(47.1)$ & $96(79.1)$ & $\begin{array}{l}100(90.0 \\
)\end{array}$ & & & & & & & & $56(52.0)$ \\
\hline Mean & $8(13.5)$ & $18(24.7)$ & $30(32.7)$ & $40(38.9)$ & $94(76.0)$ & $99(87.1)$ & & & & & & & & \\
\hline \multicolumn{15}{|c|}{ CD $(P=0.05)$, Time=2.36, Concentration=3.34, Time $X$ Concentration=5.78 } \\
\hline \multicolumn{15}{|c|}{ Effect of non-polar fraction (soluble in ethyl acetate) } \\
\hline 24 & $0(0.0)$ & $7(15.0)$ & $19(25.6)$ & $35(36.1)$ & $70(57.0)$ & $79(62.7)$ & & & & & & & & $35(32.7)$ \\
\hline 48 & $2(6.6)$ & 13(21.1) & $24(29.1)$ & $45(41.9)$ & $83(66.0)$ & 88(69.9) & & & & & & & & $42(39.1)$ \\
\hline 72 & $4(11.9)$ & $27(31.5)$ & $38(37.8)$ & $58(49.8)$ & $89(70.4)$ & $91(72.9)$ & & & & & & & & $51(45.7)$ \\
\hline Mean & $2(6.2)$ & $16(22.5)$ & $27(30.8)$ & $46(42.6)$ & $81(64.1)$ & $86(68.5)$ & & & & & & & & \\
\hline \multicolumn{15}{|c|}{ CD $(\mathrm{P}=0.05)$, Time=1.61, Concentration=2.28, Time X Concentration=3.95 } \\
\hline \multicolumn{15}{|c|}{ Effect of polar fraction (soluble in methanol) } \\
\hline 24 & & & & & & & $13(21.3)$ & $35(36.3)$ & $42(40.4)$ & & $5(47.7$ & $68(55.6)$ & $80(63.3)$ & $49(44.1)$ \\
\hline 48 & & & & & & & $16(23.5)$ & $40(39.4)$ & $47(43.3)$ & & $99(50.2$ & $73(58.7)$ & $85(67.7)$ & $53(47.1)$ \\
\hline 72 & & & & & & & $20(26.5)$ & $43(41.2)$ & $53(46.5)$ & & $2(51.2$ & $77(61.1)$ & $89(70.8)$ & $57(49.7)$ \\
\hline Mean & & & & & & & $16(23.8)$ & $40(38.9)$ & $47(43.4)$ & & $99(50.0$ & $73(58.5)$ & $85(67.3)$ & \\
\hline
\end{tabular}

(Figure in parenthesis is angular transform values) 
Table.2 Effect of different polarity fractions of calotropis latex of on growth and yield attributing parameters of brinjal crop

\begin{tabular}{|c|c|c|c|c|c|c|c|c|c|}
\hline Fraction & Dose/h & $\begin{array}{l}\text { Plant } \\
\text { Height } \\
\text { (cm) }\end{array}$ & $\begin{array}{l}\text { Root } \\
\text { Length } \\
(\mathrm{cm})\end{array}$ & $\begin{array}{l}\text { Shoot } \\
\text { Branch }\end{array}$ & $\begin{array}{l}\text { Root } \\
\text { Branch }\end{array}$ & $\begin{array}{l}\text { number } \\
\text { of galls/ } \\
\text { plant }\end{array}$ & $\begin{array}{l}\% \\
\text { Reduction } \\
\text { over } \\
\text { control }\end{array}$ & $\begin{array}{l}\text { Average } \\
\text { Yield } \\
\text { (kg/Pl.) }\end{array}$ & $\begin{array}{l}\% \text { gain } \\
\text { in yield } \\
\text { over } \\
\text { control }\end{array}$ \\
\hline Control & 0.00 & 23 & 12 & 5 & 3 & 98 & - & 1.65 & 0.00 \\
\hline \multirow{3}{*}{$\begin{array}{l}\text { Hexane } \\
\text { soluble }\end{array}$} & 0.75 & 45 & 18 & 7 & 6 & 66 & 32.65 & 2.35 & 42.42 \\
\hline & 1 & 47 & 20 & 8 & 5 & 61 & 37.75 & 2.59 & 57.00 \\
\hline & 1.25 & 52 & 22 & 10 & 7 & 52 & 46.94 & 3.5 & 112.00 \\
\hline \multirow{3}{*}{$\begin{array}{l}\text { Dichloro } \\
\text { methane }\end{array}$} & 0.75 & 44 & 19 & 6 & 5 & 64 & 34.70 & 2.15 & 30.30 \\
\hline & 1 & 43 & 18 & 6 & 5 & 55 & 43.87 & 2.35 & 42.42 \\
\hline & 1.25 & 47 & 20 & 7 & 5 & 48 & 51.00 & 2.75 & 66.66 \\
\hline \multirow{3}{*}{$\begin{array}{l}\text { Ethyl } \\
\text { acetate }\end{array}$} & 0.75 & 41 & 17 & 5 & 3 & 62 & 36.73 & 1.75 & 06.00 \\
\hline & 1 & 44 & 18 & 5 & 3 & 55 & 43.87 & 2.85 & 72.72 \\
\hline & 1.25 & 50 & 20 & 5 & 4 & 46 & 53.00 & 3.25 & 96.96 \\
\hline SEm \pm & & 2.23 & 2.50 & 0.93 & 0.91 & 4.76 & & 0.28 & \\
\hline CV (\%) & & 7.4 & 13.6 & 14.5 & 19.8 & 7.8 & & 11.1 & \\
\hline $\mathrm{CD}(\mathrm{P}=0.05)$ & & 9.5 & 7.4 & 2.7 & 2.7 & 14.0 & & 0.82 & \\
\hline
\end{tabular}

Table.3 Effect of different polarity fractions calotropis latex of on growth and yield attributing parameters of chilli crop

\begin{tabular}{|c|c|c|c|c|c|c|c|c|c|}
\hline \multirow[t]{2}{*}{ fraction } & \multirow[t]{2}{*}{ Dose/h } & \multirow{2}{*}{$\begin{array}{c}\text { Plant } \\
\text { Height } \\
\text { (cm) }\end{array}$} & \multirow[t]{2}{*}{$\begin{array}{l}\text { Shoot } \\
\text { Branch }\end{array}$} & \multirow[t]{2}{*}{$\begin{array}{l}\text { number of } \\
\text { galls/ plant }\end{array}$} & \multirow[t]{2}{*}{$\begin{array}{l}\% \text { Reduction } \\
\text { over control }\end{array}$} & \multicolumn{2}{|c|}{ Average Yield } & \multicolumn{2}{|c|}{$\begin{array}{l}\text { \% gain in yield over } \\
\text { control }\end{array}$} \\
\hline & & & & & & $\begin{array}{l}\text { Per plant } \\
(\mathrm{kg})\end{array}$ & $\begin{array}{l}\text { Per ha. } \\
\text { (Tones) }\end{array}$ & Per plant & Per ha \\
\hline Control & 0.00 & 52 & 6 & 83 & - & 0.126 & 4.7 & 0.00 & 0.00 \\
\hline \multirow{3}{*}{$\begin{array}{l}\text { Hexane } \\
\text { soluble }\end{array}$} & 0.75 & 68 & 7 & 60 & 28 & 0.177 & 7.1 & 40 & 51 \\
\hline & 1 & 70 & 7 & 58 & 30 & 0.190 & 7.3 & 51 & 55 \\
\hline & 1.25 & 72 & 7 & 50 & 40 & 0.219 & 7.8 & 74 & 66 \\
\hline \multirow{2}{*}{$\begin{array}{l}\text { Dichloro } \\
\text { methane }\end{array}$} & 1 & 61 & 7 & 50 & 40 & 0.154 & 6.1 & 22 & 30 \\
\hline & 1.25 & 70 & 7 & 46 & 45 & 0.172 & 6.9 & 30 & 47 \\
\hline \multirow[t]{3}{*}{ Ethyl acetate } & 0.75 & 66 & 6 & 59 & 29 & 0.138 & 5.3 & 10 & 13 \\
\hline & 1 & 67 & 7 & 56 & 33 & 0.147 & 5.7 & 17 & 21 \\
\hline & 1.25 & 70 & 6 & 50 & 40 & 0.160 & 6.5 & 27 & 38 \\
\hline SEm \pm & & 4.85 & 0.67 & 5.72 & & 0.016 & 0.42 & & \\
\hline CV (\%) & & 7.3 & 10.2 & 10.1 & & 9.9 & 6.7 & & \\
\hline
\end{tabular}

The EC formulations were applied as soil application after dissolving their required concentrations in one liter water. Plant height, root length, shoot branches, root branches, number of galls/plant, yield/plant and average yield/h were chosen important parameters for efficacy test of the formulations. The data presented in Table 2 for brinjal and Table 3 for chilli clearly revealed that different concentrations ranging from 0.750 to
$1.25 \mathrm{~g} / \mathrm{pot}$ of prepared formulations of extracted fractions not only brought about significant reduction in root-knot development caused by $M$. javanica but also observed to gain in root and shoot length, branch numbers etc. significantly that ultimately leads to a highly significant increase in yield of both of the crop plants. Though as compare to control, a significant improvement in plant phonological 
parameters viz., plant height, root length, number of branches etc. of both of the crop plants have been observed in almost all treatments of prepared EC formulations however, the differences within the treatments were not found significant neither with the treatments concentrations $(0.750,1.00$, $1.250 \mathrm{~g} / \mathrm{pot}$ ) nor with the solubility nature of the fractionated formulations. In case of brinjal approximately $40-50 \%$ reduction in root-knot development over control was observed at highest dose $(1.25 \mathrm{~g} / \mathrm{pot})$ of the three non-polar fractions (hexane, ethyl acetate, dichloromethane) based formulations and almost same trend was observed in case of chilli. The maximum increase in yield of brinjal to the extent of roughly $100 \%$ was observed in $1.25 \mathrm{~g} / \mathrm{pot}$ treatment of the formulation derived from hexane soluble and ethyl acetate soluble fractions whereas, dichloromethane soluble fraction based EC at the same concentration also gave nearly $60 \%$ yield enhancement. In case of chilli nearly 40 $60 \%$ yield enhancement, over control, was received in highest dose treatment $(1.250 \mathrm{~g} / \mathrm{pot})$ of all the three formulations, however in this case also, the formulation derived from hexane soluble fraction was found most active by giving a yield enhancement of $67 \%$, over control. Over results, not only shows significant improvement in plant phonological parameters but also revealed a huge gain in crop yield, which may be by the significant reduction in the root-knot development. The same kind of results has been confirmed by some of the researchers (Siddiqui and Alam, 1988; Aziz et al., 1995; Tiyagi et al., 2009). It was also reported by same authors that that leaf extracts in the form of organic additives released some phenolic compounds/nutrients which accelerated rapid root development and overall plant growth thus help the plants to develop resistance against nematode attack. The results are also in accordance with those of Tiyagi et al., (2001), Siddiqi and Alam
(1990) where Calotropis procera latex was revealed very effective in increasing the plant growth parameters and reducing the multiplication of root-knot nematode in soil whereas, Maheswari and Rajeswari (2001) revealed the effectiveness of different doses of calotropis leaf extract in reduced penetration of nematodes and increase in shoot and root weight of treated crops. Mojumder and Goswami (1987), studied Calotropis gigantea extracts on egg masses of $M$ incognita and reported a huge reduction in juvenile penetration into tomato roots. Zaki and Bhatti (1989) also observed a significant increase in growth of tomato in terms of height and weight and reduced population of $M$ javanica when $C$. procera leaves were applied to soil. In vivo application of neem cake and extracts of $C$. procera to cowpea enhanced plant growth variables, increased root weight and decreased the number of galls per plant as reported by Latif et al., (1999). Thus our current research findings can be considered as confirmative study to hypothesis that nematodes are killed after entering the root system or coming into contact with soil that contains Calotropis latex bioactive compounds. However to make the finding more valuable chemical structure elucidation of isolated compounds is required presently the work is in progress in our laboratory.

\section{References}

Abid, M., Choudhary, M. I., Maqbool, M. A. and Rahman, A. U. 1997. Preliminary screening of some plants for their nematicidal activity against Meloidogyne javanica. Nematologie Mediterranae, 25: 155-157.

Aziz, I., Ahmad, R. and Javed, N. 1995. Effect of insecticides and leaf extracts on root-dip treatment on Meloidogyne javanica infecting eggplant (Solanum 
melongena). Pak. J. Phytopathol., 7: 6870.

Begum, N., Sharma, B. and Pandey, R. S. 2013. Calotropis procera and Annona squamosa: Potential alternatives to chemical pesticides. British J. Appl. Sci. Technol., 3: 254-67.

Bhatti, D. S. and Jain, R. K. 1977. Estimation of loss in okra, tomato and brinjal yield due to Meloidogyne javanica. Indian J. Nematol., 7: 37-41.

Chitwood, D. J. 2002. Phytochemical based strategies for nematode control. Annual Review of Phytopathology 40: 221-249.

Das, D. and Mishra, S. D. 2003. Effect of neem seed powder and neem based formulations for the management of Meloidogyne incognita, Heterodera cajani and Rotylenchulus reniformis infecting pigeonpea. Ann. Pl. Protec. Sci., 11: 110-115.

Gommers, F. J. 1981. Biological interactions between nematodes and plants and their relevance to control. Helminthological Abstracts Series, B: 9-2A.

Haseeb, A. and Shukla, P. K. 2004. Management of Heterodera cajani, Meloidogyne incognita and Fusarium wilt on pigeonpea with some chemicals, bio-pesticides and bioagents. Nematologica Mediterranea 32: 217222.

Kumar, S. P., Suresh, E. and Kalavathy, S. 2013. Review on a potential herb Calotropis gigantea (L.) R. Br. Scholars Acad. J. Pharm., 2: 135-43.

Latif, L. H., Abmad, R. and Inam-ul-Haq, M. 1999. Effect of seed treatments with neem cake, neem oil and latex of oak on the germination of cowpea and its vulnerability to root-knot nematode (Meloidogyne incognita). Pakistan $J$. Phytopathology, 11: 52-55.

Maheswari, U. and Rajeswari S. 2001. Management of Root-Knot Nematode, Meloidogyne incognita Infecting
Cowpea by Calotropis Leaf Extract. Indian J. Nemotol., 31: 133-135.

Mojumder, V. and Goswami, B. K. 1987. Effect of aqeous extracts of madar (Calolropis gigantea) and amarhel (Cuscuta reflexa) on larval mortality, hatching from egg masses and subsequent penetration into tomato roots. Annals Agricultural Res., 8: 285289.

Muhammad, Z. K., Ghulam, S. and Sher, M. 2001. Control of root-knot nematode (Meloidogyne incognita) on tomato plants by using root extracts of plants. $J$. Agric. Tropics and Subtropics, 102: 143-146.

Nazir, A. C. 2013. Effect of four leaf extracts on egg hatching and juvenile mortality of root knot nematode Meloidogyne incognita. International Journal of Advanced Life Sciences 6: 68-74.

Pandey, R., Kalra, A., Katiyar, N. and Kumar, S. 2001. Nematicidal activity in flowers of some medicinal and aromatic plants. Indian J. Nematol., 31: 96- 98.

Prakash, A. and Rao, J. 1997. Botanical pesticides in agriculture. CRC, Lewis Publishers Boca Raton, New York, London, Tokyo. Pp. 461.

Prasad, D., Ram, D. and Ahmad, I. 2002. Management of plant parasitic nematodes by the use of botanicals. Ann. Pl. Protec. Sci. 10: 360-364.

Reddy, D. D. R. 1985. Analysis of crop losses in tomato due to Meloidogyne javanica. Indian J. Nematol., 15: 55-59.

Salawu, E. O. 1992a. Efficacy of organic soil amendments in controlling Heterodera sacchari on sugarcane. In: The biology and control of nematode pests of food crops in Africa. Proceedings of the first regional symposium of African Society of Nematologists. B. Fawole, O.A. Egunjobi, S.O. Adesiyan, O.A. Babatola, and A.A Idowu (Eds.). 
University of Ibadan, Nigeria 26-29 July, 1992, 175-182.

Sasser, J. N., Carter, C. C. and Hartmann, K.

M. 1984. Standardization of host suitability studies and reporting of resistance to root-knot nematode. Crop Nematode Research and Control Project, Raleigh, North Carolina. Schmutterer, H. 1981. Ten years of neem research in the Federal Republic of Germany, pp. 21-51. In $\mathrm{H}$. Schmutterer, K.R.S. Ascher, H. Rembold, (Eds.), Natural Pesticides from the Neem Tree (Azadirachta indica A. Juss.). Proc Ist Intern. Neem Conference, GTZ, Eschborn, Germany.

Sethi, C. L. and Prasad, D. 1962. In vitro toxicity of DBCP to some phytophagous nematodes and hatchability of Heterodera cajani. Indian Journal of Nematology, 12: 6572.

Sheth, F. 2011. Range of seasonal phytochemical variations in Calotropis procera (Ait.) R. Br. Int. J. Med. Aroma. Plants, 1: 180-3.

Siddiqi, M. A. and Alam, M. M. 1990. Potential of plant latex as botanical nematicide. IPM Practitioner, 12: 6-8.

Siddiqui, M. A., Haseeb, A. and Alam, M. M.1987. Evaluation of nematicidal properties in some latex bearing plants. Indian J. Nematol., 17: 99-102.

Sundararaju, P., Padmanaban, B. and Sathiamoorthy, S. 2003. Efficacy of certain botanicals against root-lesion nematode, Pratylenchus coffeae in banana. Nematol. Meditt., 31: 201-205.
Taylor, R. W. D. 2000. Methyl bromide - is phase out on schedule? Pesticide Outlook, 11: 54-57.

Tiyagi, S. A., Khan, A. V. and Alam, M. M. 2001. Role of oil-seed cakes for the management of plant-parasitic nematodes and soil-inhabiting fungi on lentil and mungbean. Arch. Phytopathol. Pfl., 23:453-472.

Tiyagi, S. A., Mahmood, I. and Rizvi, R. 2009. Application of some latex bearing plants for the management of phytonematodes infecting tomato and eggplant. Thai J. Agrl. Sci., 42: 183189.

Upadhyay, K. D., Dwivedi, K. and Uttam, S. K. 2003. Effect of some plant extracts on the mortality and hatching of Meloidogyne incognita and Heterodera cajani infesting pigeon pea. Nematol. Meditt., 31: 28-32.

Verma, B. S., Verma, K. V., Sangwan, K. V. and Dhinsda, K. S. 1989. Toxicity of some indigenous plant extracts to rootknot, seed-gall and citrus nematodes. Pesticides, 23: 25-27.

Vijayalakshmi, K. and Goswami, K. 1985. Effect of aqueous extract of madar (Calotropis giganta) and amarbel (Cuscuta reflexa) on larval mortality, hatching and penetration of Meloidogyne incognita. Indian $J$. Nematol., 15: 265.

Zaki, F. A. and Bbatti, O. S. 1989. Phytotherapeutic effect of some plant leaves on Meloidgyne javanica infecting tomato plants. Nematol. Medit., 17: 7172.

\section{How to cite this article:}

Lalit Kumar, Abhilasha Srivastava, Bansa Singh and Khare, A.P. 2018. Isolation of Biocidal Compounds of Calotropis Latex and their in vitro and in vivo Effect on the Mortality of Root Knot Nematode (Meloidogyne javanica) in Brinjal and Chilli. Int.J.Curr.Microbiol.App.Sci. 7(04): 3361-3372. doi: https://doi.org/10.20546/ijcmas.2018.704.380 